\title{
Theoretical study of the stability and reactivity of salicylic acid isomers by the DFT method
}

\author{
Hayat EL Ouafy ${ }^{a^{*}}$, Mouna Aamor ${ }^{\mathrm{a}}$, Mustapha Oubenali ${ }^{\mathrm{a}}$, Mohamed Mbarki ${ }^{\mathrm{a}}$, Aziz EL Haimouti ${ }^{\mathrm{b}}$ and \\ Tarik EL Ouafy
}

\begin{abstract}
${ }^{a}$ Laboratory of Engineering in Chemistry and Physics of Matter, Department of Chemistry and Environment, Faculty of Sciences and Technics, Sultan Moulay Slimane University, Beni Mellal, Morocco

${ }^{b}$ Laboratory of Engineering in Chemistry and Physics of Matter, Department of Physics and Chemistry, Polydisciplinary Faculty of Khouribga, Sultan Moulay Slimane University, Beni Mellal, Morocco

\begin{tabular}{l}
\hline C H R O N I C L E \\
\hline Article history: \\
Received August 21, 2021 \\
Received in revised form \\
October 25, 2021 \\
Accepted February 2, 2022 \\
Available online \\
February 2, 2022 \\
\hline Keywords: \\
Ortho-hydroxybenzoic acid \\
Meta-hydroxybenzoic acid \\
Para-hydroxybenzoic acid \\
DFT \\
Chemical descriptor
\end{tabular}

A B S T R A C T

The FT-IR spectrum of salicylic acid (SA) was studied in the region $10-4000 \mathrm{~cm}^{-1}$. The optimized molecular geometry and fundamental vibration frequencies are interpreted using structural optimizations based on the Functional Density Theory (DFT) method. Additionally, we used B3LYP / 6-311G (d, p) to determine the chemical descriptor, the ionization potential (I), the electron affinity $(A)$, the chemical potential $(\mu)$, the chemical hardness $(\eta)$. Nonlinear optical descriptors (NLO) such as dipole moment $(\mu)$, polarizability $(\alpha)$, first hyperpolarizability $(\beta)$ and second hyperpolarizability $(\gamma)$, 3D maps of HOMO and LUMO orbitals, lengths and Bond angles of salicylic acid isomers are also determined by both DFT and MP2 (The Møller-Plesset theory of order 2 perturbation) methods. The overall descriptors and the non-linear optical properties confirmed that salicylic acid is the reactive molecule and para-hydroxybenzoic acid is the stable molecule. An electrostatic molecular potential (MEP) study was also performed to determine the reactivity of molecules.
\end{abstract}

\section{Introduction}

Salicylic acid or ortho-hydroxybenzoic acid (Fig. 1A) is an aromatic organic compound, one of the three isomers of hydroxybenzoic acid (along with 3-hydroxybenzoic acid or meta-hydroxybenzoic acid and 4-hydroxybenzoic acid or parahydroxybenzoic acid), consisting of a benzene ring substituted by a carboxyl group (benzoic acid) and a hydroxyl group (phenol) in the ortho position. It is a colorless crystalline solid that is naturally found in certain plants, including willow, used as a medicine and as a precursor of acetylsalicylic acid, aspirin. It plays an essential role in regulating growth, development, interactions of plants with other organisms, and in the response of plants to environmental stresses. Salicylic acid levels have been shown to increase in plants exposed to ozone, UV rays, and after infection with a pathogen. Salicylic acid can be synthesized from phenylalanine via cinnamic and benzoic acids or can be released from its conjugates such as glucosides or glucose esters. ${ }^{1}$ Salicylic acid is an anti-inflammatory drug, chemically known as ortho-hydroxybenzoic acid. It is used as an ingredient in many drugs to treat psoriasis, calluses, corns, pillars of keratosis, and warts. Salicylic acid is characterized by its ability to relieve pain and reduce fever. These medicinal characteristics, especially the relief of fever, have been known since Antiquity. This colorless crystalline acid of the molecular formula $\mathrm{C}_{7} \mathrm{H}_{6} \mathrm{O}_{3}$ is generally used in organic synthesis, and it plays the role of a plant hormone. They have been loaded with a wide range of molecules from antioxidants to antibiotics, anticancer and anti-inflammatory drugs and used in nano-architecture for drug delivery in oral systems as tablets and capsule fillers, in bone cement, in active food packaging, and in the antibacterial and anticorrosion protective coating as well as for nanocomposites, membranes, or films. ${ }^{2}$ Therefore, an effective and practical determination of SA is very important. ${ }^{3}$ In general, the action of salicylates is achieved by the SA contents, although some of the characteristic properties of acetylsalicylic acid are their ability for protein acetylation. The esters in the carboxylic or * Corresponding author.

E-mail address: elouafyhayat@gmail.com (H. E. Ouafy)

C 2022 by the authors; licensee Growing Science, Canada doi: $10.5267 /$ j.ccl.2022.2.002 
phenolic groups change the power of the salicylate's toxicity. ${ }^{4}$ Extensive experimental and theoretical research has focused on the elucidation of the structure and normal vibrations of salicylic acid and its derivatives. They also studied the substitution effect on the spectral properties of salicylic acid derivatives. ${ }^{5}$ Meta-Hydroxybenzoic acids (Fig. 1B) can be naturally formed from Meta-chlorobenzene acid by certain bacteria of the genus Pseudomonas. It has been used as an intermediate in the synthesis of plasticizers, resins, pharmaceuticals, etc. It has a role as a bacterial metabolite and a plant metabolite. ${ }^{6}$ Para-Hydroxybenzoic acid (Fig. 1C) is produced industrially by the Kolbe reaction of potassium phenolate with carbon dioxide. It can also be synthesized in the laboratory by heating potassium salicylate with potassium carbonate to $240^{\circ} \mathrm{C}$, followed by treatment with an acid. It serves mainly as a precursor for the preparation of its esters, known as parabens, which are used as preservatives in cosmetics. It is also used to make polyacrylates. ${ }^{7}$

In this work, we were interested in the study of the structural and spectroscopic properties of salicylic acid isomers. We used DFT and MP2 methods to calculate the thermochemical descriptors (the optimization of the geometries, the lengths and the bond angles of the molecules, the energies and the densities of the frontier molecular orbitals HOMO and LUMO, the electronic chemical potential, electronegativity, chemical hardness, overall softness, overall electrophilic index, overall nucleophilic index, nonlinear magnetic optical properties) to compare the stability and reactivity of these molecules depending on the position of the $\mathrm{OH}$ group and the study of their sites of electrophilic and nucleophilic attacks by electrostatic potential molecular.
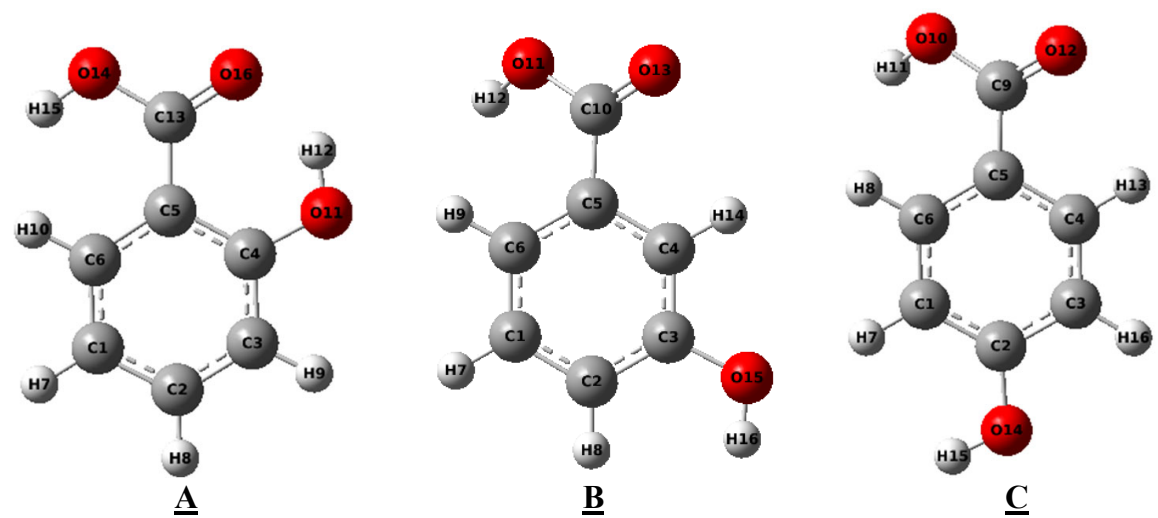

Fig. 1. Optimized molecular structure of (A) ortho-Hydroxybenzoic acid, (B) meta-Hydroxybenzoic acid, (C) paraHydroxybenzoic acid

\section{Results and discussion}

\subsection{Infrared vibration spectra of the $S A$ molecule}

Infrared (IR) radiation is electromagnetic radiation with a wavelength greater than that of the visible spectrum but shorter than that of microwaves. Our current work accounts for the IR spectra of SA recorded by Gaussian 09 theoretically simulated. This simulation was carried out by the DFT method. In this work, the following steps were followed: optimization of the geometry, calculation of the IR specters. Spectra have characteristics distinct from low-frequency vibration modes caused by intramolecular motion. ${ }^{8}$ The detailed vibrational assignments of the fundamental principles of salicylic acid as well as observed and calculated the number of waves. ${ }^{9}$ Theoretical harmonic frequencies $\left(\mathrm{cm}^{-1}\right)$ and infrared intensities for salicylic acid with the B3LYP method using a basic set 6-311G $(\mathrm{d}, \mathrm{p})$. The spectra calculated for salicylic acid are requested in Fig. 2.

Table. 1. Calculated and experimental vibrational low frequencies in the region up to $4000 \mathrm{~cm}^{-1}$ for salicylic acid $(v$, stretching; $\delta$, in-plane bending).

\begin{tabular}{|c|c|c|}
\hline$v$, stretching $\left(\mathrm{cm}^{-1}\right) / \delta$, in-plane bending $\left(\mathrm{cm}^{-1}\right)$ & Calculated ''FT-IR', & Experimental ''FT-IR'” 10 \\
\hline Vo-H & 3300 & 3233 \\
\hline $\mathbf{v}_{\mathrm{C}-\mathrm{H}}$ & 2999 & $2999-2831$ \\
\hline $\mathbf{v}_{\mathrm{C}=\mathbf{O}}$ & $1670-1692$ & $1652-1670$ \\
\hline $\mathbf{v}_{\mathbf{C}=\mathbf{C}}$ & 1558 & $1558-1610$ \\
\hline $\mathbf{v}_{\mathrm{C}-\mathrm{C}}$ & $1440-1500$ & $1444-1503$ \\
\hline $\mathbf{v}_{\mathrm{C}-\mathrm{O}}$ & 1290 & 1296 \\
\hline VC-OH & $1156-1250$ & $1156-1248$ \\
\hline$\delta_{\text {O-H }}$ & 1350 & 1324 \\
\hline$\delta_{\mathrm{C}-\mathrm{H}}$ & 756 & $759-669$ \\
\hline
\end{tabular}

FT-IR spectrum (Table 1) showed characteristic vibrational peaks at wavenumber $3300 \mathrm{~cm}^{-1}$ and $2999 \mathrm{~cm}^{-1}$ that were assigned to $\mathrm{OH}$ and $\mathrm{C}-\mathrm{H}$ stretching, respectively. The $\mathrm{C}=\mathrm{O}(\mathrm{COO}-)$ asymmetric and symmetric stretching were assigned to the IR peaks observed at $1670-1692 \mathrm{~cm}^{-1}$ and $1386 \mathrm{~cm}^{-1}$, respectively. Further, IR peaks that appeared at $1558 \mathrm{~cm}^{-1}$ were attributed to $\mathrm{C}=\mathrm{C}$ (phenolic) multiple peaks. The $\mathrm{C}-\mathrm{C}$ stretching peaks were observed at $1440-1500 \mathrm{~cm}^{-1}$. The $\mathrm{O}-\mathrm{H}$ 
(phenolic) bending was assigned to the IR peak that appeared at $1350 \mathrm{~cm}^{-1}$. The COO- $(\mathrm{C}-\mathrm{O})$ stretching and C-OH (phenolic) stretching were assigned to IR peaks that appeared at $1290 \mathrm{~cm}^{-1}$ and $1156-1250 \mathrm{~cm}^{-1}$, respectively. The vibrational peaks that appeared at $756-669 \mathrm{~cm}^{-1}$ were attributed to $=\mathrm{C}-\mathrm{H}$ bending. The FT-IR data observed for salicylic acid by the DFT method are like their experimental counterparts.

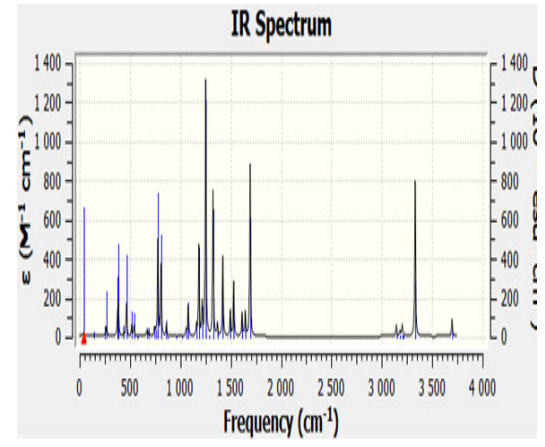

(A)

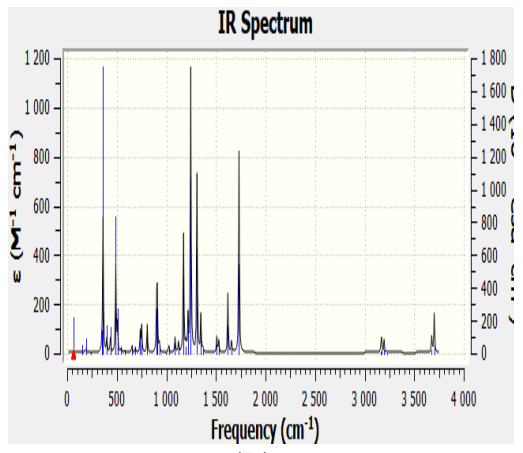

(B)

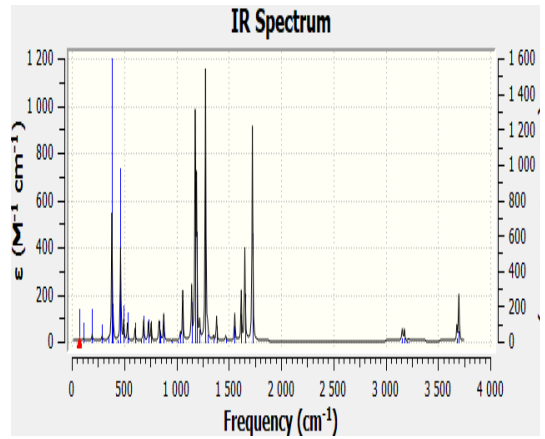

(C)

Fig. 2. The infrared spectrum of (A) ortho-Hydroxybenzoic acid, (B) meta-Hydroxybenzoic acid, (C) para-Hydroxybenzoic acid by the B3LYP method

\subsection{Quantum chemical calculation}

The main orbitals involved in chemical stability are the highest occupied molecular orbital (HOMO) and the lowest unoccupied molecular orbital (LUMO). The HOMO represents the capacity to yield an electron while the LUMO represents the capacity to gain an electron. The HOMO and LUMO energies are calculated by the B3LYP/6-311G (d, p) method. Electronic absorption corresponds to the transition from the ground to the first excited state described by an electronic excitation from the highest occupied molecular orbital (HOMO) to the lowest unoccupied molecular orbital (LUMO) ${ }^{11}$ with the optimized structures of salicylic acid isomers are illustrated in Fig. 3.

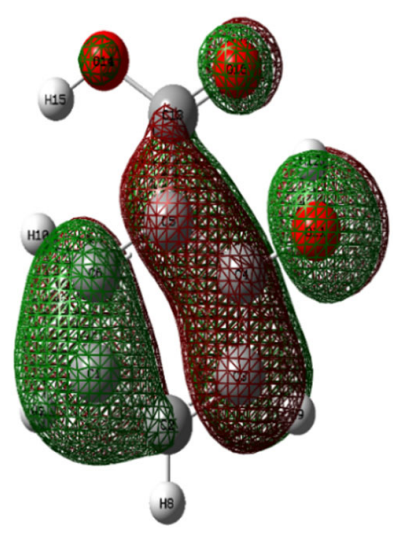

A

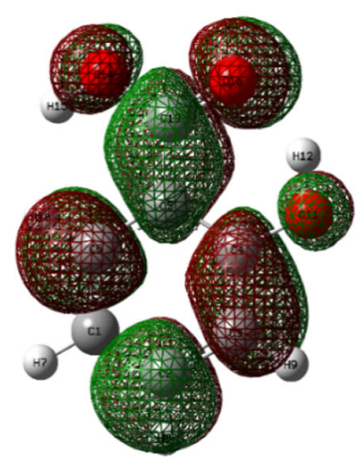

A

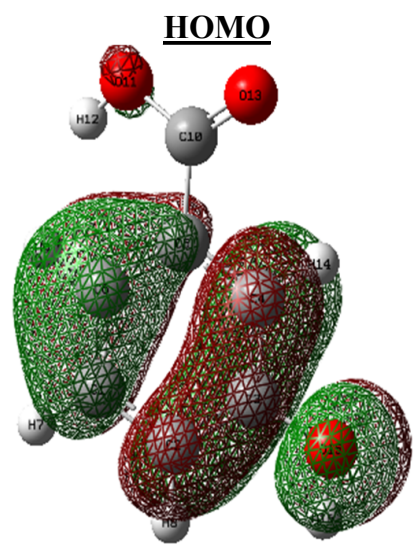

B

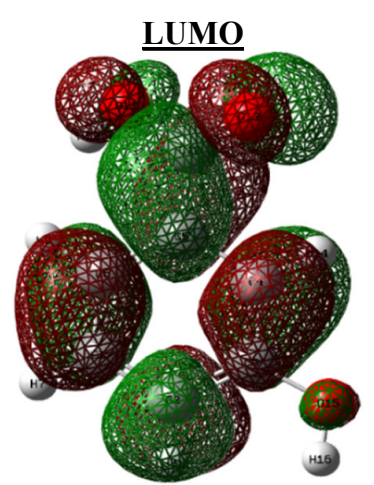

B

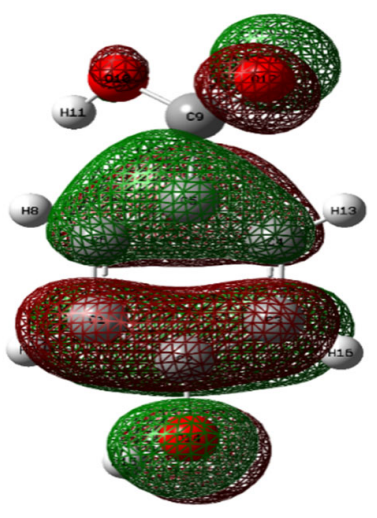

$\underline{\mathbf{C}}$

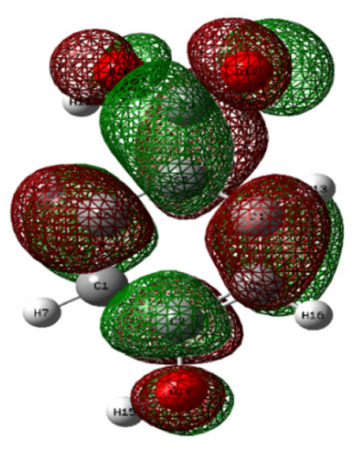

$\underline{\mathrm{C}}$

Fig. 3. HOMO and LUMO of (A) ortho-Hydroxybenzoic acid, (B) meta-Hydroxybenzoic acid, (C) para-Hydroxybenzoic acid 
Many applications are available on the utilization of the HOMO and LUMO gap as a quantum descriptor in correlates in different biochemical and chemical systems. ${ }^{12,13}$ The following quantum descriptors have been calculated from the optimized structure obtained:

Ionization potential: $\mathrm{I}=-\mathrm{E}_{\mathrm{HO} \mathrm{O}}$

Electronic affinity: $\quad \mathrm{A}=-\mathrm{E}_{\mathrm{LUMO}}$

Absolute electronegativity: $\quad \chi=\frac{\mathrm{I}+\mathrm{A}}{2}$

Overall hardness: $\quad \eta=\mathrm{I}-\mathrm{A}$

Overall softness: $\sigma=\frac{1}{\eta}=\frac{1}{\mathrm{E}_{\mathrm{LUMO}}-\mathrm{E}_{\text {Номо }}}$

Electronic chemical potential: $\quad \mu=-\frac{(\mathrm{I}+\mathrm{A})}{2}$

Maximum charge transfer: $\Delta \mathrm{Nmax}=-\frac{2}{\eta}$

Overall electrophilicity: $\quad \omega=\frac{\mu^{2}}{2 \eta}$

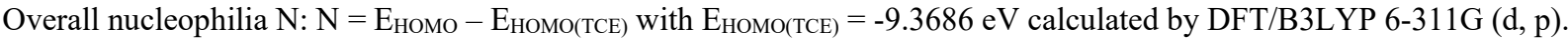

In order to highlight the electrophilic/nucleophilic character of salicylic acid isomers, we calculated: the ionization potential I, the electronic affinity A, the electronic chemical potential $\mu$, the absolute electronegativity $\chi$, the overall hardness $\eta$, the overall softness $\sigma$, the overall electrophilicity index $\omega$, the index of overall nucleophilic $\mathrm{N}$ and the maximum charge transfer $\Delta \mathrm{N}_{\max }$ (Table 2).

Table. 2. Theoretical parameters calculated of salicylic acid isomers by B3LYP/6-311G (d, p).

\begin{tabular}{|c|c|c|c|c|c|c|c|c|c|c|c|c|}
\hline Parameters (eV) & Elumo & Еномо & $\Delta \mathbf{E}$ & I & $\mathbf{A}$ & $\mu$ & $\chi$ & $\eta$ & $\sigma$ & $\omega$ & $\mathbf{N}$ & $\Delta \mathbf{N}_{\max }$ \\
\hline Salicylic acid & -2.142 & -6.884 & 4.742 & 6.884 & 2.142 & -4.513 & 4.513 & 4.742 & 0.210 & 2.147 & 2.484 & 0.951 \\
\hline $\begin{array}{c}\text { Metahydroxybenzoic } \\
\text { acid }\end{array}$ & -1.881 & -7.023 & 5.142 & 7.023 & 1.881 & -4.452 & 4.452 & 5.142 & 0.194 & 1.927 & 2.345 & 0.865 \\
\hline $\begin{array}{l}\text { Parahydroxybenzoic } \\
\text { acid }\end{array}$ & -1.708 & -7.055 & 5.347 & 7.055 & 1.708 & -5.72 & 5.72 & 5.347 & 0.187 & 3.059 & 2.313 & 1.069 \\
\hline
\end{tabular}

The energy gap of salicylic acid (4,742 eV) is lower than the energy gap corresponds to meta-hydroxybenzoic acid (5.142 $\mathrm{eV}$ ) and para-Hydroxybenzoic acid $(5.347 \mathrm{eV})$, thus ortho-Hydroxybenzoic acid is the reactive molecule given its low gap value and para-hydroxybenzoic acid is the stable molecule. Hardness gives an idea of the relative duration of a molecule to store electrons in its environment. According to the table, we have the molecule of para-hydroxybenzoic acid at great hardness $(\eta=5.347 \mathrm{eV})$ compared to meta-hydroxybenzoic acid $(\eta=5.142 \mathrm{eV})$ and salicylic acid $(\eta=4.742 \mathrm{eV})$ so parahydroxybenzoic acid contains more electrons in its environment compared to other molecules. Softness is the ease with which the cationic $\mathrm{A}^{+}$molecule can receive electrons, or anionic A- to lose electrons. Para-hydroxybenzoic acid is, therefore, more difficult to receive or lose electrons than meta-hydroxybenzoic acid and salicylic acid. The electrophilicity index of para-hydroxybenzoic acid $(\omega=3.059 \mathrm{eV})$ is higher than that of salicylic acid $(\omega=2.147 \mathrm{eV})$ and $m e t a-$ hydroxybenzoic acid $(\omega=1.927 \mathrm{eV})$ which shows that the reactivity of para-hydroxybenzoic acid vis-a-vis nucleophilic attack is greater than that of salicylic acid and meta-hydroxybenzoic acid. The nucleophilicity index of salicylic acid $(\mathrm{N}=$ $2.484 \mathrm{eV})$ is higher than that of para-hydroxybenzoic acid $(\mathrm{N}=2.313 \mathrm{eV})$ and meta-hydroxybenzoic acid $(\mathrm{N}=2.345 \mathrm{eV})$ which shows that the reactivity of 1 salicylic acid vis-a-vis electrophilic attack is greater than those of other molecules. The maximum charge transfers of para-hydroxybenzoic acid $(\Delta \mathrm{Nmax}=1.069 \mathrm{eV})$ is greater than that of salicylic acid $(\Delta \mathrm{Nmax}=0.951 \mathrm{eV})$ and meta-hydroxybenzoic acid $(\Delta \mathrm{Nmax}=0.865 \mathrm{eV})$.

\subsection{Non-linear optical properties}

Intermolecular interactions such as drug-vitamin are widely understood by dipole moments and the energetic terms of hyperpolarization of the first and second-order. The dipole moment $(\mu)$, the polarizability $(\alpha)$, the first hyperpolarizability $(\beta)$ and the second hyperpolarizability $(\gamma)$ are calculated using a basic set of DFT and MP2 on the basis of the B3LYP 6$311 \mathrm{G}$ approach $(\mathrm{d}, \mathrm{p})$. The complete equations to calculate the amplitude of the total static dipole moment $(\mu)$, the polarizability $(\alpha)$, the first hyperpolarizability $(\beta)$ and the second hyperpolarizability $(\gamma)$, using the components $\mathrm{x}, \mathrm{y}, \mathrm{z}$ of 09W The Gaussian output is as follows: ${ }^{14}$

$$
\begin{aligned}
& \mu=\left(\mu_{x}^{2}+\mu_{y}^{2}+\mu_{z}^{2}\right)^{1 / 2} \\
& \alpha=\frac{\left(\alpha_{x x}+\alpha_{y y}+\alpha_{z z}\right)}{3} \\
& \beta=\left(\beta_{x}^{2}+\beta_{y}^{2}+\beta_{z}^{2}\right)^{1 / 2} \\
& \beta_{x}=\beta_{x x x}+\beta_{x y y}+\beta_{x z z} \\
& \beta_{y}=\beta_{y y y}+\beta_{x x y}+\beta_{y z z} \\
& \beta_{z}=\beta_{z z z}+\beta_{x x z}+\beta_{y y z} \\
& <\gamma>=\frac{1}{5}\left(\gamma_{x x x x}+\gamma_{y y y y}+\gamma_{z z z z}+2\left[\gamma_{x x y y}+\gamma_{y y z z}+\gamma_{x x z z}\right]\right)
\end{aligned}
$$


The results for the dipole moment, linear polarizability, first hyperpolarizability, and second hyperpolarizability of salicylic acid isomers are tabulated in Table 3. The dipole moment of the molecules is again calculated using DFT/MP2 and method B3LYP with basic set 6-311G $(\mathrm{d}, \mathrm{p})$. The dipole moment reflects the distribution of molecular charges and is given as a three-dimensional vector. Consequently, it can be utilized as a descriptor to represent the charge movement through the molecule as a function of the negative and positive charge centers. Dipole moments are necessarily determined for neutral molecules. For charged molecules, its values depend on the orientation and the choice of the origin of the molecule.

The results indicate that the calculated value of the dipole moment of para-Hydroxybenzoic acid by the MP2 method $(7.68 \mathrm{D})$ is greater than that of ortho-Hydroxybenzoic acid and meta-Hydroxybenzoic acid, which reflects the stability of para-Hydroxybenzoic acid compared to the other molecules studied.

The results reveal that the values of the polarizability, first-order hyperpolarizability, and second-order hyperpolarizability tensors of salicylic acid calculated by the DFT and MP2 methods are elevated in all three directions compared to the values of the tensors of ortho-Hydroxybenzoic acid and meta-Hydroxybenzoic acid. So orthoHydroxybenzoic acid is the most polarizable and is the most chemically active.

The difference sometimes in the values calculated by the two methods is explained by the MP2 method which is an ab initio method based on the calculation of the wave function (depends on $4 \mathrm{~N}$ variables: three spatial coordinates and the fourth spin) and energies of molecular orbitals. The fundamental idea of the functional density theory (DFT) is to reduce the number of variables by replacing the wave function with a function which is the electron density $\rho$ ( $x, y, z)$ which does not depend on 3 variables only.

Table. 3. Electric dipole moments (Debye) by two methods DFT and MP2 of (A) ortho-Hydroxybenzoic acid, (B) metaHydroxybenzoic acid, (C) para-Hydroxybenzoic acid calculated using B3LYP / 6-311G (d, p).

\begin{tabular}{|c|c|c|c|c|c|c|c|}
\hline & & \multicolumn{2}{|c|}{$\mathbf{A}$} & \multicolumn{2}{|c|}{ B } & \multicolumn{2}{|c|}{ C } \\
\hline & Parameters & DFT & MP2 & DFT & MP2 & DFT & MP2 \\
\hline \multirow{4}{*}{ Dipole moment (Debye) } & $\mu_{\mathbf{x}}$ & 4.95 & 5.11 & -5.03 & -3.76 & 4.43 & 5.32 \\
\hline & $\mu_{y}$ & 3.97 & 4.28 & -0.69 & -3.83 & 5.37 & 5.44 \\
\hline & $\mu_{\mathrm{z}}$ & 0.78 & 0.85 & 5.57 & 0.17 & 1.19 & 1.02 \\
\hline & $\mu$ & 6.40 & 6.73 & 7.54 & 5.37 & 7.06 & 7.68 \\
\hline \multirow{4}{*}{$\begin{array}{l}\text { Polarizability } \\
\text { (Debye) }\end{array}$} & $\boldsymbol{\alpha}_{\mathbf{x x}}$ & -65.32 & -61.51 & -59.06 & -59.82 & -70.65 & -75.27 \\
\hline & $\alpha_{y y}$ & -52.73 & -52.73 & -57.25 & -58.69 & -49.94 & -50.03 \\
\hline & $\alpha_{z z}$ & -58.49 & -60.33 & -59.42 & -60.57 & -59.52 & -60.51 \\
\hline & $\boldsymbol{\alpha}$ & -58.85 & -58.19 & -58.57 & -59.69 & -60.03 & -62.04 \\
\hline \multirow{10}{*}{$\begin{array}{c}\text { First } \\
\text { Hyperpolarizability } \\
\text { (Debye) }\end{array}$} & $\beta_{\mathbf{x x x}}$ & 77.93 & 80.69 & 82.02 & 105.28 & -47.11 & -45.27 \\
\hline & $\beta_{x y y}$ & 10.49 & 12.49 & -4.40 & 22.06 & 0.75 & 9.38 \\
\hline & $\beta_{x z z}$ & -6.28 & -6.80 & -4.44 & -8.19 & 8.68 & 13.09 \\
\hline & $\beta_{y y y}$ & 11.23 & 12.36 & 21.50 & 22.06 & -0.15 & -25.87 \\
\hline & $\beta_{x x y}$ & 41.14 & 44.10 & 28.09 & 24.60 & 6.67 & 0.38 \\
\hline & $\beta_{y z z}$ & 1.52 & 1.81 & -6.23 & -3.54 & 6.20 & 3.46 \\
\hline & $\beta_{z z z}$ & 0.76 & 0.91 & 1.16 & 2.52 & 18.58 & 0.21 \\
\hline & $\beta_{\mathrm{xxz}}$ & 1.85 & 2.13 & 15.56 & 5.51 & 12.39 & 1.03 \\
\hline & $\beta_{y y z}$ & 4.19 & 4.44 & 2.25 & 3.20 & 13.82 & 0.73 \\
\hline & $\boldsymbol{\beta}$ & 98.47 & 152.13 & 87.15 & 127.24 & 59.9 & 31.76 \\
\hline \multirow{7}{*}{$\begin{array}{c}\text { Second } \\
\text { Hyperpolarizability } \\
\text { (Debye) }\end{array}$} & $\gamma_{\mathbf{x x x x}}$ & -1163.78 & -1109.3 & -1288.5 & -1246.3 & -1677.0 & -1746.5 \\
\hline & $\gamma_{y y y y}$ & -462.22 & -544.36 & -521.04 & -511.80 & -355.22 & -349.05 \\
\hline & $\gamma_{\mathrm{zzzz}}$ & -149.63 & -61.46 & -60.97 & -74.77 & -69.22 & -71.06 \\
\hline & $\gamma_{x x y y}$ & -249.31 & -254.16 & -322.26 & -328.12 & -304.07 & -309.12 \\
\hline & $\gamma_{\mathrm{yyzz}}$ & -106.44 & -114.64 & -106.22 & -107.07 & -81.37 & -81.95 \\
\hline & $\gamma_{\mathbf{x x z z}}$ & -241.88 & -202.91 & -230.28 & -234.99 & -268.62 & -271.92 \\
\hline & $\gamma$ & -594.18 & -571.73 & -637.60 & -429.92 & -681.91 & -698.51 \\
\hline
\end{tabular}

\subsection{Thermodynamic parameters}

We determined for each molecule the enthalpy $\mathrm{H}$, the entropy S, and the free enthalpy G (Table 4). The enthalpy $\mathrm{H}$ is the sum of the internal energy of a system and the product of its pressure by its volume. Entropy $\mathrm{S}$ is characterized by the degree of disorder or unpredictability of the information contained in a system. We have found that para-Hydroxybenzoic acid has a lower $\mathrm{G}$ energy. This result means that para-Hydroxybenzoic acid is thermodynamically more stable.

Table 4. Thermodynamic parameters of (A) ortho-Hydroxybenzoic acid, (B) meta-Hydroxybenzoic acid, (C) paraHydroxybenzoic acid

\begin{tabular}{cccc}
\hline Molecules & $\Delta \mathbf{H}(\mathbf{K c a l} / \mathbf{m o l})$ & $\Delta \mathbf{S}(\mathbf{K c a l} / \mathbf{m o l} / \mathbf{K})$ & $\Delta \mathbf{G ~}(\mathbf{K c a l} / \mathbf{m o l})$ \\
\hline A & -311130.30 & 0.0893 & -311156.52 \\
B & -311140.11 & 0.0890 & -311166.63 \\
\hline C & -311164.72 & 0.0901 & -311191.57 \\
\hline
\end{tabular}




\subsection{Bond length and angle properties}

In this article, we will deepen our studies on selective bond lengths $(\AA)$ and angles (degrees). The MP2 level has been used with the DFT method, the utility of which is to describe the molecular physical and chemical properties. ${ }^{15}$

Table 5 and Table 6 show the comparison of the optimized bond length and the angle between experimental and calculated atomic numbered positions as (Fig. 1) the optimized structure using a periodic DFT and MP2 calculation corresponds exactly to an experimental result. The DFT and MP2 results were very similar and in good condition according to the experimental structure. The study of the geometric product, therefore, showed an excellent agreement between theoretical and experimental results.

Table 5. Bond lengths $(\AA)$ of (A) ortho-Hydroxybenzoic acid, (B) meta-Hydroxybenzoic acid, (C) para-Hydroxybenzoic acid

\begin{tabular}{|c|c|c|c|c|c|c|c|}
\hline \multirow[b]{2}{*}{ Bond length $(\AA)$} & \multicolumn{2}{|c|}{$\mathbf{A}$} & \multicolumn{2}{|c|}{ B } & \multicolumn{2}{|c|}{$\mathbf{C}$} & \multirow[b]{2}{*}{$\operatorname{Exp}^{16}$} \\
\hline & DFT & MP2 & DFT & MP2 & DFT & MP2 & \\
\hline $\mathrm{C}_{1}-\mathrm{C}_{2}$ & 1.3952 & 1.4058 & 1.3964 & 1.4072 & 1.3983 & 1.4042 & 1.40 \\
\hline $\mathrm{C}_{3}-\mathrm{C}_{4}$ & 1.3954 & 1.4028 & 1.394 & 1.4019 & 1.3969 & 1.3981 & 1.40 \\
\hline $\mathrm{C}_{4}-\mathrm{C}_{5}$ & 1.4048 & 1.4112 & 1.3977 & 1.4058 & 1.4073 & 1.4137 & 1.41 \\
\hline $\mathrm{C}_{5}-\mathrm{C}_{6}$ & 1.3851 & 1.3822 & 1.3867 & 1.3854 & 1.3885 & 1.3804 & 1.38 \\
\hline $\mathrm{C}_{4}-\mathrm{O}_{11}$ & 1.3657 & 1.3664 & ---- & ---- & ---- & ---- & 1.36 \\
\hline $\mathrm{C}_{5}-\mathrm{C}_{13}$ & 1.4744 & 1.4698 & ---- & ---- & ---- & ---- & 1.47 \\
\hline $\mathrm{C}_{13}-\mathrm{O}_{16}$ & 1.2379 & 1.2345 & ---- & ---- & ---- & ---- & 1.23 \\
\hline $\mathrm{C}_{13}-\mathrm{O}_{14}$ & 1.3013 & 1.3031 & ---- & ---- & ---- & ---- & 1.30 \\
\hline $\mathrm{C}_{2}-\mathrm{O}_{14}$ & ---- & ---- & ---- & ---- & 1.3866 & 1.406 & 1.39 \\
\hline $\mathrm{C}_{5}-\mathrm{O}_{9}$ & ---- & ---- & ---- & ---- & 1.4829 & 1.4802 & 1.48 \\
\hline $\mathrm{C}_{9}-\mathrm{O}_{12}$ & ---- & ---- & ---- & ---- & 1.2274 & 1.2301 & 1.22 \\
\hline $\mathrm{C}_{9}-\mathrm{O}_{10}$ & ---- & ---- & ---- & ---- & 1.3931 & 1.4083 & 1.40 \\
\hline $\mathrm{C}_{5}-\mathrm{O}_{13}$ & ---- & ---- & 1.39 & 1.4008 & ---- & ---- & 1.39 \\
\hline $\mathrm{C}_{5}-\mathrm{C}_{10}$ & ---- & ---- & 1.4902 & 1.4931 & ---- & ---- & 1.49 \\
\hline $\mathrm{C}_{10}-\mathrm{O}_{13}$ & ---- & ---- & 1.2256 & 1.2393 & ---- & ---- & 1.22 \\
\hline $\mathrm{C}_{10}-\mathrm{O}_{11}$ & ---- & ---- & 1.3899 & 1.3901 & ---- & ---- & 1.39 \\
\hline
\end{tabular}

Table 6. Angles $\left(\theta^{\circ}\right)$ of (A) ortho-Hydroxybenzoic acid, (B) meta-Hydroxybenzoic acid, (C) para-Hydroxybenzoic acid

\begin{tabular}{|c|c|c|c|c|c|c|c|}
\hline \multirow[b]{2}{*}{ Angles $\left(\theta^{\circ}\right)$} & \multicolumn{2}{|c|}{$\mathbf{A}$} & \multicolumn{2}{|c|}{ B } & \multicolumn{2}{|c|}{$\mathrm{C}$} & \multirow[b]{2}{*}{$\operatorname{Exp}^{16}$} \\
\hline & DFT & MP2 & DFT & MP2 & DFT & MP2 & \\
\hline $\mathrm{C}_{1}-\mathrm{C}_{2}-\mathrm{C}_{3}$ & 120.00 & 120.56 & 119.5277 & 119.2669 & 120.4813 & 120.6865 & 120.5 \\
\hline $\mathrm{C}_{2}-\mathrm{C}_{3}-\mathrm{C}_{4}$ & 119.99 & 120.34 & 120.5359 & 120.8117 & 119.5738 & 119.4868 & 120.3 \\
\hline $\mathrm{C}_{3}-\mathrm{C}_{4}-\mathrm{C}_{5}$ & 119.99 & 119.96 & 119.7539 & 119.326 & 120.8666 & 120.3628 & 119.4 \\
\hline $\mathrm{C}_{4}-\mathrm{C}_{5}-\mathrm{O}_{6}$ & 120.00 & 118.83 & 120.0426 & 120.4783 & 118.804 & 119.2391 & 119.4 \\
\hline $\mathrm{C}_{3}-\mathrm{C}_{4}-\mathrm{O}_{11}$ & 116.98 & 116.87 & ---- & ---- & ---- & --- & 116.0 \\
\hline $\mathrm{C}_{5}-\mathrm{C}_{13}-\mathrm{O}_{16}$ & 112.88 & 123.02 & ---- & ---- & ---- & ---- & 123.0 \\
\hline $\mathrm{C}_{5}-\mathrm{C}_{13}-\mathrm{O}_{14}$ & 116.98 & 116.93 & ---- & ---- & ---- & ---- & 117.8 \\
\hline $\mathrm{C}_{3}-\mathrm{C}_{2}-\mathrm{O}_{14}$ & ---- & ---- & ---- & ---- & 116.6821 & 116.1039 & 116.2 \\
\hline $\mathrm{O}_{10}-\mathrm{C}_{9}-\mathrm{O}_{12}$ & ---- & ---- & ---- & ---- & 118.6512 & 119.1471 & 119.1 \\
\hline $\mathrm{O}_{11}-\mathrm{C}_{10}-\mathrm{O}_{13}$ & ---- & ---- & 119.0166 & 119.3528 & ---- & ---- & 119.2 \\
\hline $\mathrm{C}_{4}-\mathrm{C}_{3}-\mathrm{O}_{15}$ & ---- & ---- & 116.5897 & 116.1304 & ---- & ---- & 116.4 \\
\hline
\end{tabular}

\subsection{Molecular electrostatic potential}

Molecular electrostatic potentials (MEP) give detailed information for studies on chemical reactivity of a compound. The spatial distribution and the values of the electrostatic potential determine the attack of an electrophilic or of a nucleophilic agent as the primary event of a chemical reaction. Furthermore, the three-dimensional distribution of the electrostatic potential is largely responsible for the binding of a substrate at the active site of a receptor. ${ }^{17}$ The molecular electrostatic potential (MEP) is mainly used in the form of the reactivity map showing the most likely regions for the electrophile attack of point reagents loaded on organic molecules. It is very important in molecular modeling studies. Contour MEP, the map offers a simple tool to predict how different geometries can interact. The total electronic density and the MEP surface of the molecules studied are constructed by B3LYP / 6-311 Method G (d, p). Total electronic density mapped with the electrostatic potential surface, the electrostatic contour map potential of salicylic acid isomers is shown in Fig. 4 and Fig. 5. The color scheme for the MESP surface is red, rich in electrons, partially negative charge; blue, electrondeficient, partially positive charge; light blue, slightly electron-deficient region; yellow region, slightly rich in electrons; green, neutral, respectively. Blue represents electropositive and red the electronegative regions, respectively. ${ }^{18}$

Nucleophilic attack sites are C13, C10, and C9 for ortho-Hydroxybenzoic acid, meta-Hydroxybenzoic acid, and paraHydroxybenzoic acid, respectively. On the other hand, the electrophilic attacks can occur in regions of negative potential corresponding to $(\mathrm{O} 11, \mathrm{O} 14, \mathrm{O} 16),(\mathrm{O} 15, \mathrm{O} 11, \mathrm{O} 13)$ and $(\mathrm{O} 14, \mathrm{O} 10, \mathrm{O} 12)$ for ortho-Hydroxybenzoic acid, metaHydroxybenzoic acid, and para-Hydroxybenzoic acid, respectively. 


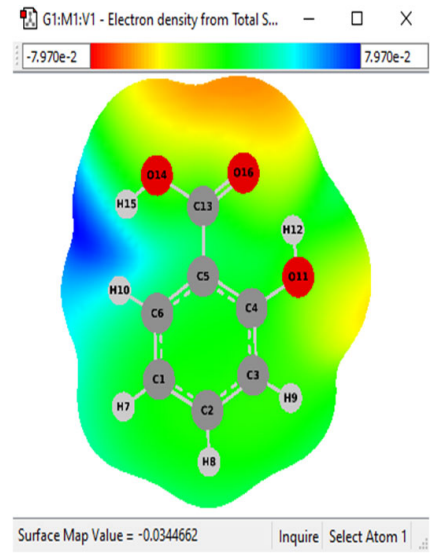

$\underline{\mathbf{A}}$

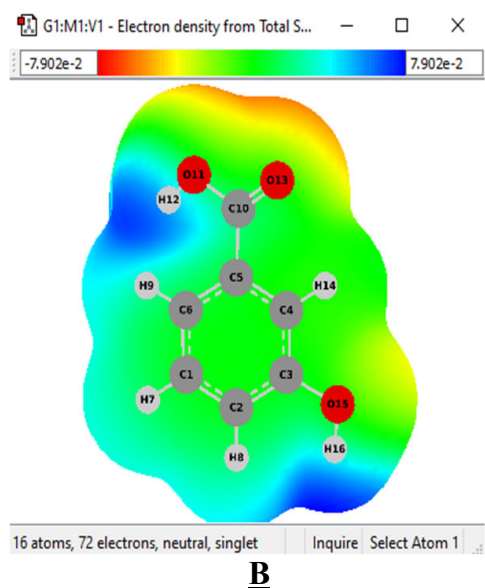

$\underline{B}$

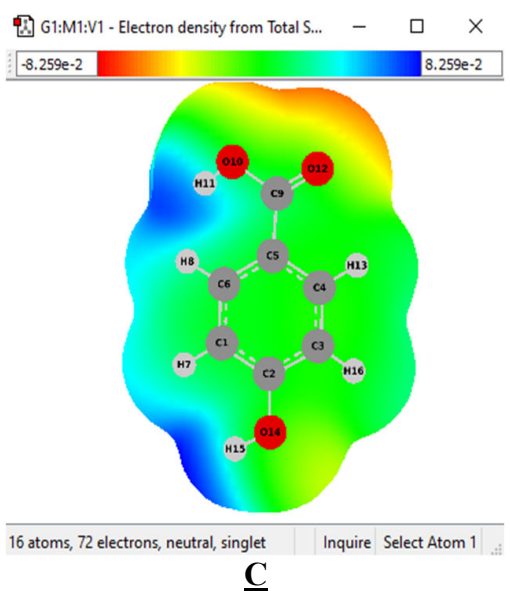

$\underline{\mathbf{C}}$

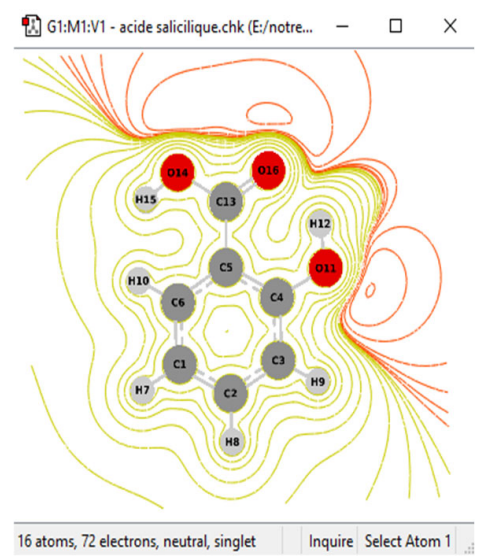

$\underline{\mathbf{A}}$

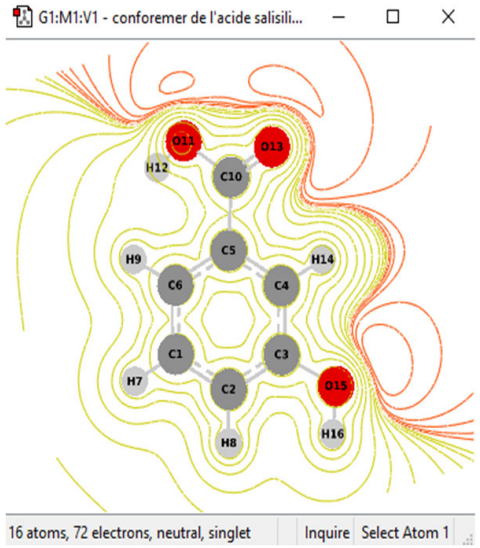

$\underline{\mathbf{B}}$

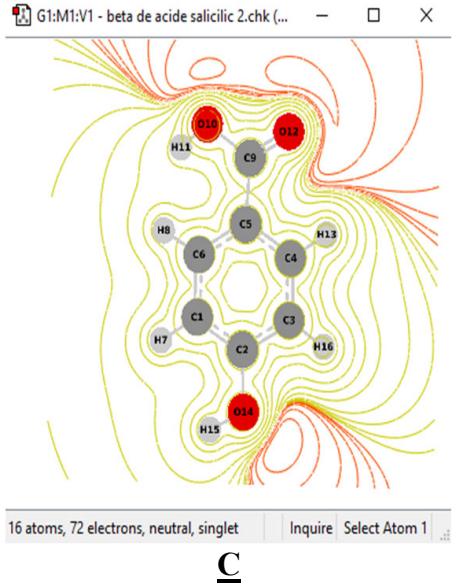

Fig. 5. Contour electrostatic potential around the molecule of salicylic acid isomers

\section{Conclusion}

Vibration frequencies are determined at theoretical wavenumbers calculated from DFT/B3LYP methods using a 6$311 \mathrm{G}(\mathrm{d}, \mathrm{p})$ basis set. In addition, HOMO and LUMO energy deviations describe the possible charge, transfer interactions taking place in the molecule and the determination of the theoretical molecular structures of salicylic acid isomers by B3LYP/6-311G (d, p) with two methods DFT and MP2. The MEP surface can lead to an understanding of the properties and activity of molecules. The linear polarizability $(\alpha)$, first hyperpolarizability $(\beta)$ and second hyperpolarizability $(\gamma)$ values of the studied molecule were calculated. The energy gap of salicylic acid is less than the energy gap corresponding to metahydroxybenzoic acid, para-hydroxybenzoic acid, therefore ortho-hydroxybenzoic acid is the reactive molecule given its difference in low value, and para-hydroxybenzoic acid is the stable molecule. The calculated results of the dipole moment of para-hydroxybenzoic acid by the MP2 method $(7.68 \mathrm{D})$ are higher than that of ortho-hydroxybenzoic acid and metahydroxybenzoic acid, which reflects the stability of the para-hydroxybenzoic acid compared to the other molecules studied. In summary, the DFT/B3LYP/6-311G (d,p) geometries are in good agreement with the MP2/B3LYP/6-311G(d,p) method. DFT/B3LYP/6-311G (d,p) proved to be a good computational method to predict infrared spectroscopy results.

\section{Computational method}

The optimized geometry of salicylic acid isomers and the vibration frequencies were calculated by the B3LYP 6-311G $(\mathrm{d}, \mathrm{p})$ method. ${ }^{19}$ All the calculations of this study were carried out with the Gaussian 09 Program ${ }^{20}$. The length and the angle of connection have been fully optimized by two methods DFT and MP2. The DFT method we used to include the popular local method, gradient correction. ${ }^{21,22}$ The following quantum the chemical indices have been taken into account: the energy of the highest occupied molecular orbit $\left(\mathrm{E}_{\text {HOMO }}\right)$, the energy of the lowest unoccupied molecular orbit ( $\left.\mathrm{E}_{\mathrm{LUMO}}\right)$, the energy band gap $\Delta \mathrm{E}=\mathrm{E}_{\mathrm{HOMO}}-\mathrm{E}_{\mathrm{LUMO}}$, the quantum descriptors, the electronic affinity $(\mathrm{A})$, the ionization potential (I) and the atomic partial charges were calculated for the two structures from the potential electrostatic surface (ESP) according to the same theory of levels. ${ }^{23,24}$

\section{References}

1. Bandurska, H., \& Stroiński, A. (2005) The effect of salicylic acid on barley response to water deficit. Acta. Physiol. Plant. 27(3), 379-386. 
2. Spepi A., lessio S., Celia D., Alfonso P., Davide P., José-Gonzalez R., Vincenzo I., \& Maria R.T. (2016) Experimental and DFT characterization of halloysite nanotubes loaded with salicylic acid. J. Phys. Chem. C. 120 (47), $26759-26769$.

3. De Zhang W., Hong Y.X., Yu Y.X., Ye J.S., \& Zhang J.Q. (2010) Electrochemical oxidation of salicylic acid at wellaligned multiwalled carbon nanotube electrode and its detection. J. Sol. State. Electrochem. 14(9), 1713-1718.

4. Torriero A.J., Luco J.M., Sereno L., \& Raba J. (2004) Voltammetric determination of salicylic acid in pharmaceuticals formulations of acetylsalicylic acid. Talanta. 62(2), 247-254.

5. Karabacak M., \& Kurt M. (2009) The spectroscopic (FT-IR and FT-Raman) and theoretical studies of 5-bromo-salicylic acid. J. Mol. Struct. 919 (1-3), 215-222.

6. Johnston H.W., Briggs G.G., \& Alexander M. (1972) Metabolism of 3-chlorobenzoic acid by a pseudomonad. Soil. Boil. Biochem. 4 (2), 187-190.

7. Antoine P., Didier R., \& Jean V.W. (2001) Influence of $\mathrm{pH}$ and chloride anion on the photocatalytic degradation of organic compounds Part I Effect on the benzamide and para-hydroxybenzoic acid in TiO2 aqueous solution. Appl. Catal. B-Environ. 35 (2), 117-124.

8. Singh Y.P., Das R., \& Singh R.A. (2007) Numerical simulation of the internal vibrations of COOH group in aminosalicylic acids. African. J. Biochem. 1(2), 019-023.

9. Krishnakumar V., \& Mathammal R. (2009) Density functional and experimental studies on the FT-IR and FT-Raman spectra and structure of benzoic acid and 3,5-dichloro salicylic acid. J. Raman. Spectrosc. 40 (3), 264-271.

10. Mahendra K.T., Alice B., Dahryn T., Harish S., Khemraj B., \& Snehasis J. (2015) Fourier Transform Infrared and Ultraviolet-Visible Spectroscopic Characterization of Biofield Treated Salicylic Acid and Sparfloxacin. Nat. Prod. Chem. Res. 5 (3), 1-6.

11. Kavitha E., Sundaraganesan N., Sebastian S., \& Kurt M. (2010) Molecular structure, anharmonic vibrational frequencies and NBO analysis of naphthalene acetic acid by density functional theory calculations. Spectrochim. Acta - Part A. Mol. Biomol. Spectrosc. 77 (11), 612-619.

12. Thanikaivelan P., Subramanian V., Raghava Rao J., \& Unni Nair B. (2000) Application of quantum chemical descriptor in quantitative structure activity and structure property relationship. Chem. Phys. Lett. 323 (1-2), 59-70.

13. Uzzaman M., Hasan M.K., Mahmud S., Fatema K., \&Matin, M.M. (2021) Structure-based design of new diclofenac: Physicochemical, spectral, molecular docking, dynamics simulation and ADMET studies. Inform. Medic. Unloc. 25, $100677,1-11$

14. Suresh S., Gunasekaran S., \& Srinivasan S. (2014) Spectroscopic (FT-IR, FT-Raman, NMR and UV-Visible) and quantum chemical studies of molecular geometry, Frontier molecular orbital, NLO, NBO and thermodynamic properties of salicylic acid. Spectrochim. Acta - Part A. Mol. Biomol. Spectrosc. 132 (3), 130-141.

15. Dobado J.A., \& Molina J. (1999) Adenine-Hydrogen Peroxide System: DFT and MP2 Investigation. J. Phys. Chem. A. $103(24), 4755-4761$.

16. Saito S., Inerbaev T.M., Mizuseki H., Igarashi N., \& Kawazoe Y. (2006) Terahertz vibrational modes of crystalline salicylic acid by numerical model using periodic density functional theory. Japanese J. Appl. Physics. Part. 1 Regul. Pap. Short. Notes. Rev. Pap. 45 (5R), 4170-4175.

17. Maps T.F. (1994) Representation of molecular electrostatic potentials by topological feature maps. J. Am. Chem. SOC. $116(11), 4608-4620$.

18. Hathwar V.R., Pal. R., \& Guru Row T.N. (2010) Charge density analysis of crystals of nicotinamide with salicylic acid and oxalic acid: An insight into the salt to cocrystal continuum. Cryst. Growth. Des. 10 (8), 3306--3310.

19. Sebastian S., Sylvestre S., Jayabharathi J., Ayyapand S., Amalanathan M., \& Oudayakumar K. (2015) Study on conformational stability, molecular structure, vibrational spectra, NBO, TD-DFT, HOMO and LUMO analysis of 3,5dinitrosalicylic acid by DFT techniques. Spectrochim. Acta - Part A Mol. Biomol. Spectrosc. 136(4), 1107-1118.

20. Islam, N., Islam, M.D., Rahman, M.R., \& Matin, M.M. (2021) Octyl 6-O-hexanoyl- $\beta$-D-glucopyranosides: Synthesis, PASS, antibacterial, in silico ADMET, and DFT studies. Curr. Chem. Lett., 10 (4), 413-426.

21. Muhammad, D., Matin, M.M., Miah, S.M.R., \& Devi, P. (2021) Synthesis, antimicrobial, and DFT studies of some benzyl 4-O-acyl- $\alpha$-L-rhamnopyranosides. Orbital: Electron. J. Chem., 13(3), 250-258.

22. Liu L., \& Gao H. (2012) Molecular structure and vibrational spectra of ibuprofen using density function theory calculations. Spectrochim. Acta - Part A Mol. Biomol. Spectrosc. 89(11), 201-209.

23. Zhou L., Lv Y.L., Hu Y.X., Zhao J.H., Xia X., \& Li X. (2018) Experimental and theoretical investigations of 1,3,5tris(4-aminophenoxy)benzene as an effective corrosion inhibitor for mild steel in $1 \mathrm{M} \mathrm{HCl.} \mathrm{J.} \mathrm{Mol.} \mathrm{Liq.,} \mathrm{249} \mathrm{(3),} \mathrm{179-}$ 187.

24. Kumer, A., Chakma, U., Matin, M.M., Akash, S., Chando, A., \& Howlader, D. (2021) The computational screening of inhibitor for black fungus and white fungus by D-glucofuranose derivatives using in silico and SAR study. Org. Commun., 14(4), 305-322.

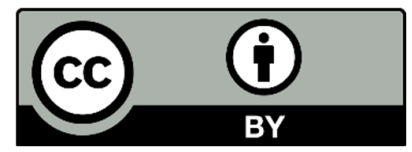

(C) 2022 by the authors; licensee Growing Science, Canada. This is an open access article distributed under the terms and conditions of the Creative Commons Attribution (CC-BY) license (http://creativecommons.org/licenses/by/4.0/). 